\title{
ICSO 2018
}

\section{Optical Communications Downlink from a $1.5 \mathrm{U}$ CubeSat: OCSD Program}

T.S. Rose, D.W. Rowen, S. LaLumondiere, N.I. Werner, R. Linares, A. Faler, J. Wicker, C.M. Coffiman, G.A. Maul, D.H. Chien, A. Utter, R.P. Welle, and S.W. Janson 


\section{NASA OSCD Mission Overview \& Status}

- OCSD funded by NASA's Small Spacecraft Technology Program

- 1U Cubesat: $10 \times 10 \times 10 \mathrm{~cm}$

- Pathfinders: quick to space

- Comm Goal: demonstrate optical downlink from a CubeSat in LEO

- Data rates: 50 Mbps threshold; 200 Mbps goal

- Body-mounted laser at $1.06 \mu \mathrm{m}$

- Beam pointing using only spacecraft ACS: star trackers

- Two vehicles, AC-7B,C, $1.5 \mathrm{U}$, currently in LEO orbit

- Launched Nov. 13, 2017 aboard Orbital ATK's Cygnus resupply vehicle for NASA's ISS

- $450 \mathrm{~km} ; 51.6^{\circ}$

- Alignment of vehicles essentially complete; alignment to be monitored over time

- BER data acquired at 50, 100 and $200 \mathrm{Mbps}$ for AC-7B 


\section{AC-7 Subsystems and Components}

$1.5 \mathrm{U:} 10 \times 10 \times 15 \mathrm{~cm}$

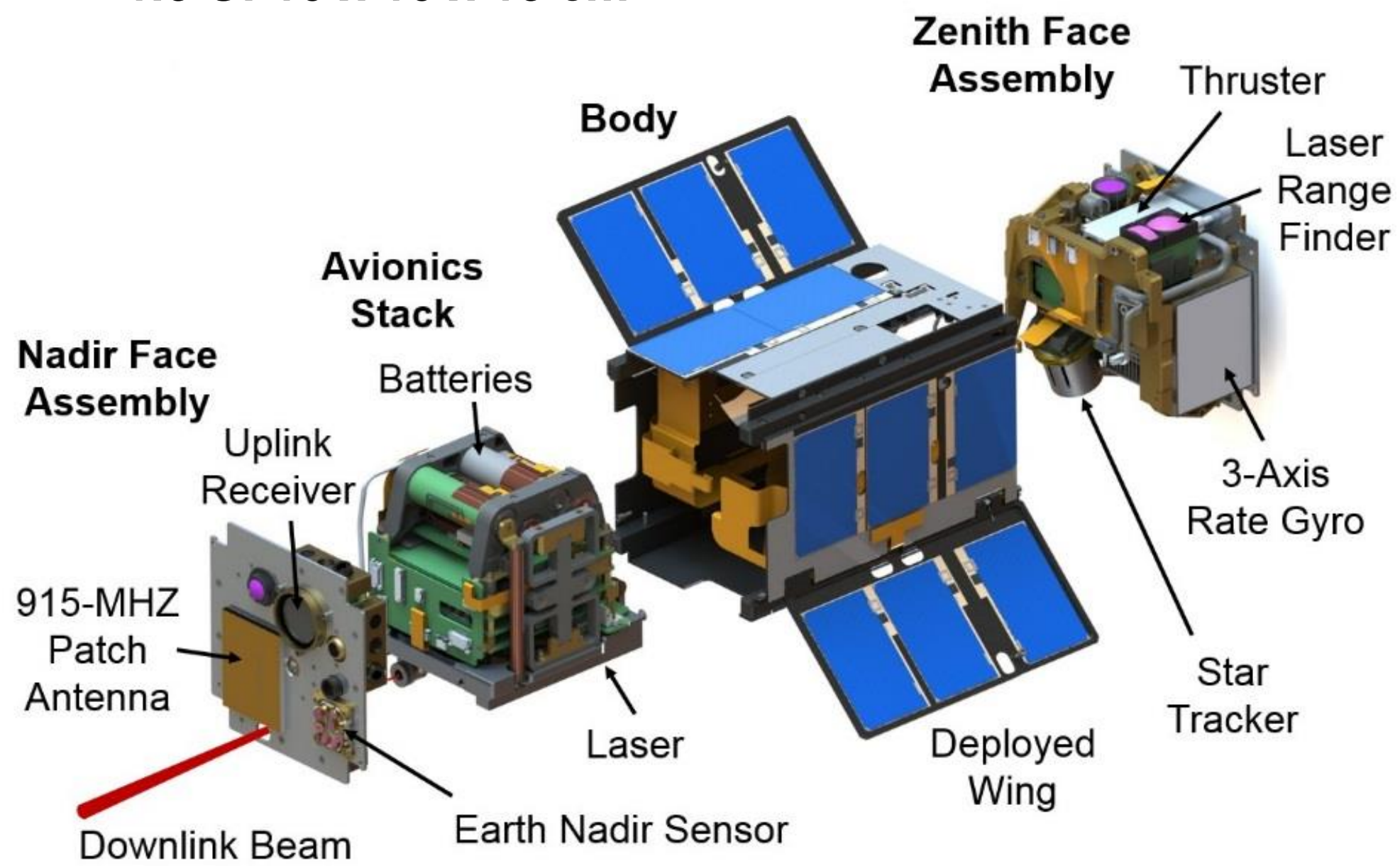




\section{AC-7B\&C as Delivered}

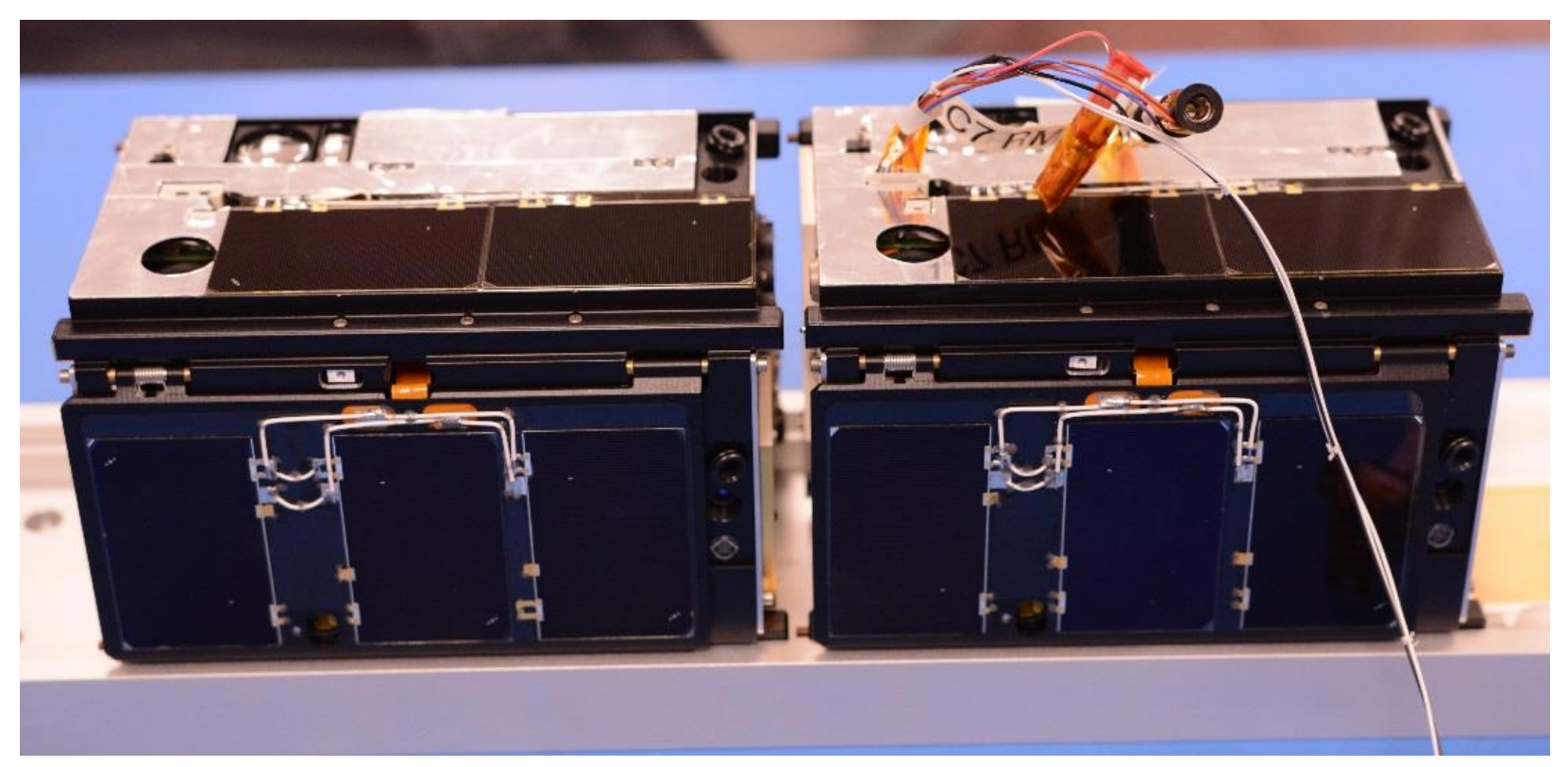

$1.5 \mathrm{U:} 10 \times 10 \times 15 \mathrm{~cm} ; 2.3 \mathrm{~kg}$ 


\section{Laser Transmitter: Simplified Block Diagram}

Master Oscillator Power Amplifier Configuration

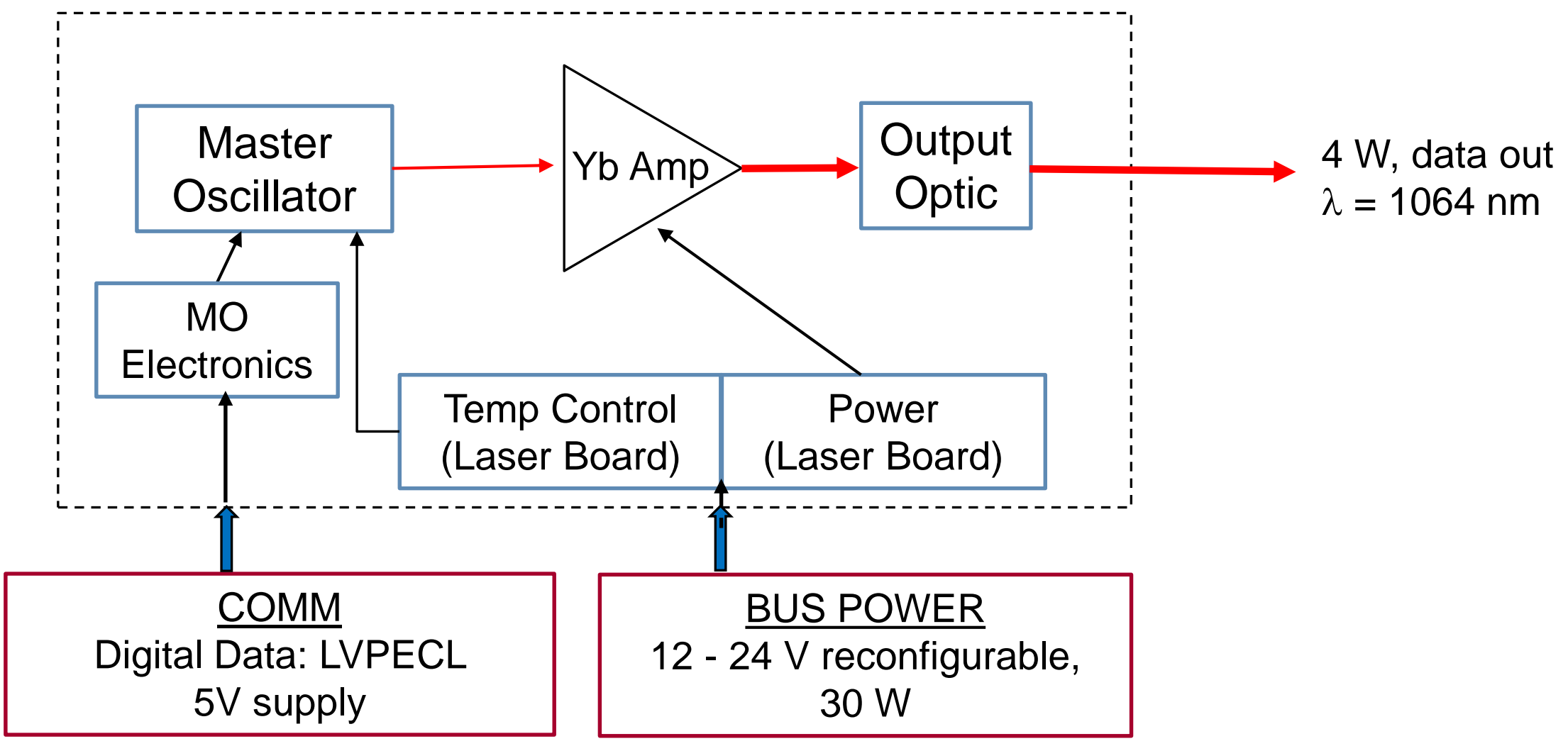




\section{AC-7 Laser Transmitter Design}

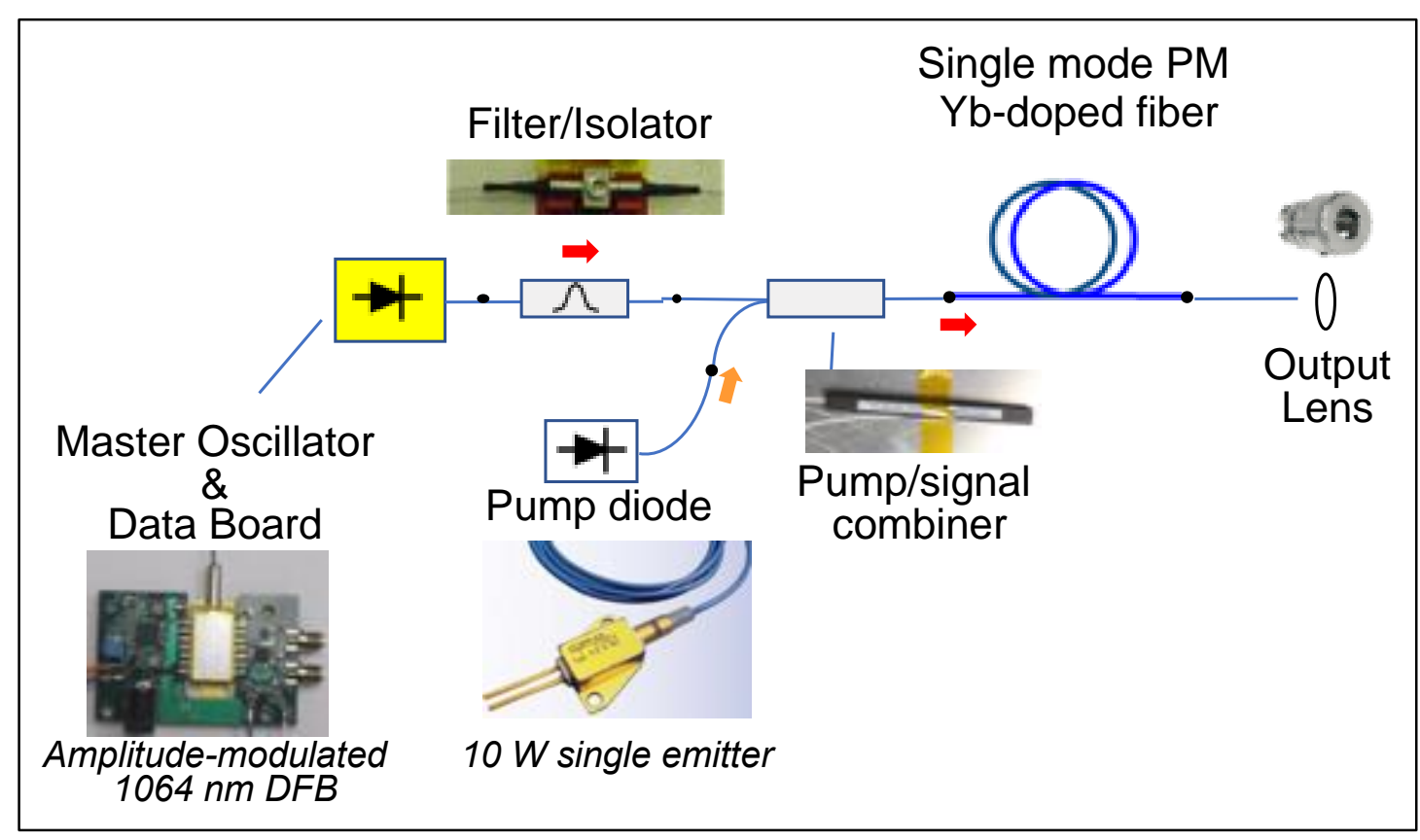

- Gain-switched laser diode + 1-stage fiber amp

- Operation at $1.06 \mu \mathrm{m}$

- 4 W max; 20\% wallplug efficiency

- Passively cooled; $\Delta \mathrm{T}$ capability $\sim 25^{\circ}$

- In space operating on $A C-7 B, C$,

- AC11 launch pending late 2018 


\section{AC7 Laser Tx OOK Waveforms}

\section{Mbps}

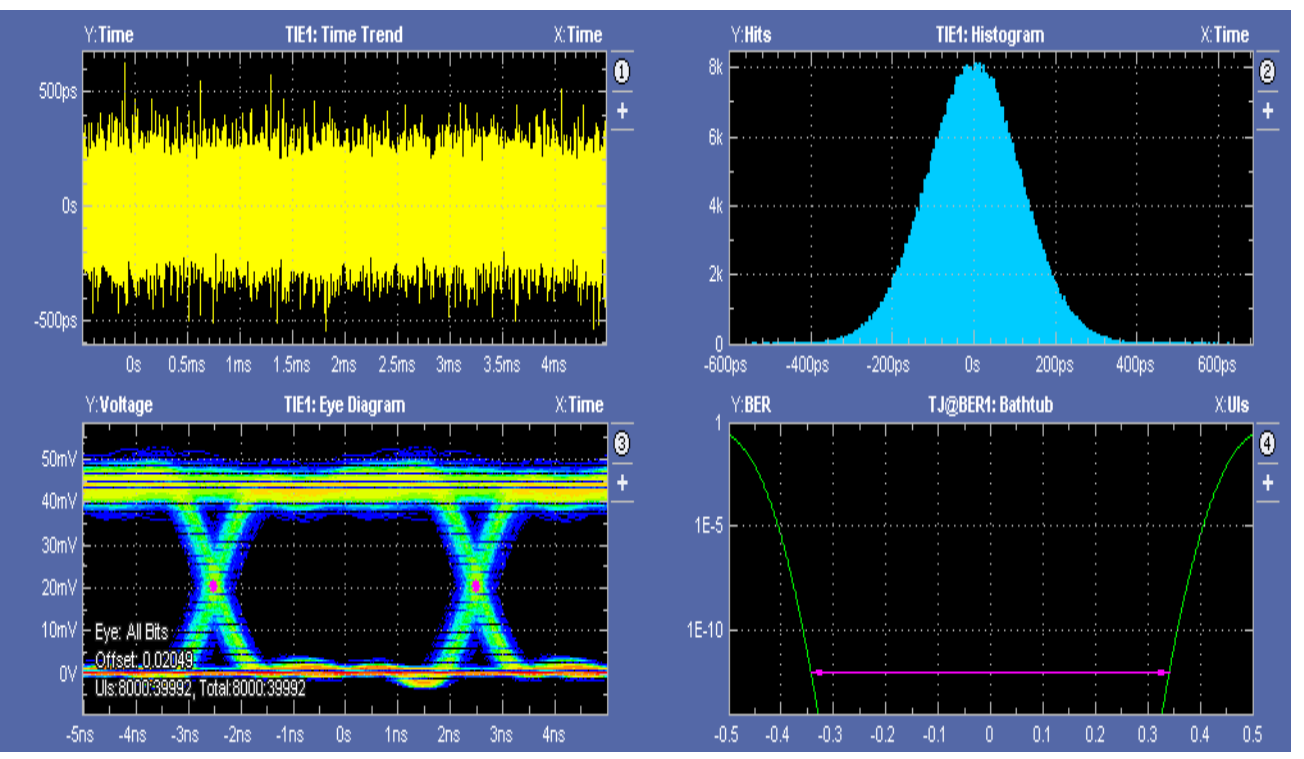

Jitter/histogram

Eye Pattern/Opening-BER projection

- Current OCSD mission only targeting 50 to $200 \mathrm{Mbps}$

- Data rate limitations not due to Tx but from Rx electronics available for program

- Pending mission data rates $\geq 200 \mathrm{Mbps}$ 


\section{Local and Remote Optical Ground Station}

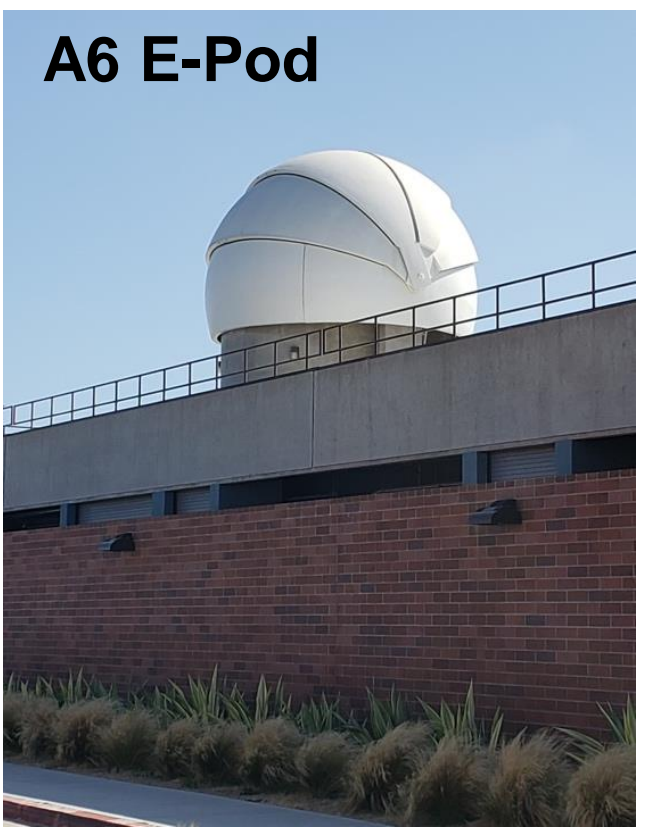

\section{Mt. Wilson}

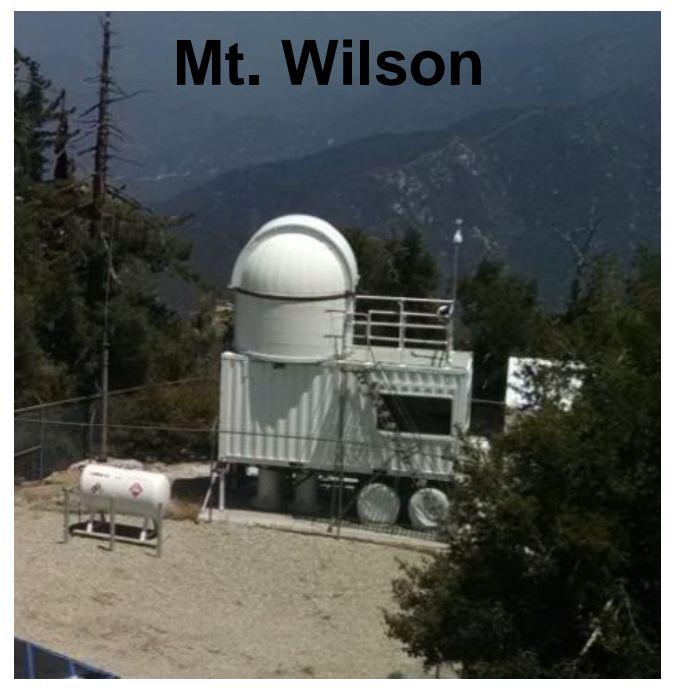

8
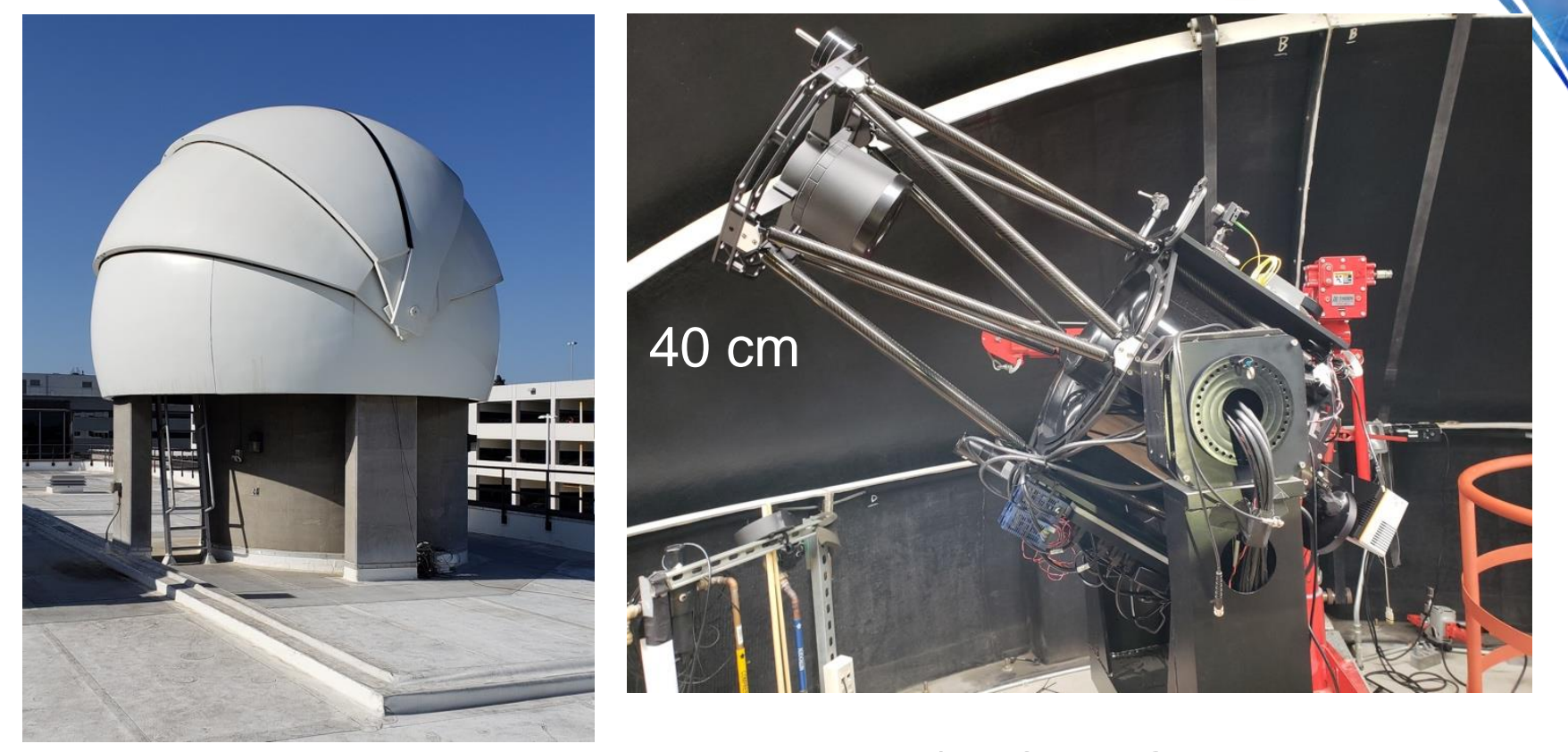

- APD detector/NFOV InGaAs camera $\left(\sim 0.2^{\circ}\right)$

- WFOV InGaAs camera ( $\left.2^{\circ}\right)$

- Control software: gimbal, data, GPS timing

- Current downlink being performed locally (A6): sea level

- Future downlinks to be done at Mt. Wilson for improved performance \& automated capabilities: $5700 \mathrm{ft}$ 


\section{AC-7B Ground Station Illumination : 5-17-2018} Early alignment stage: 1 deg scan

AC7-B Ground Station Illumination Progression: 5-17-2018

$6: 41: 17$

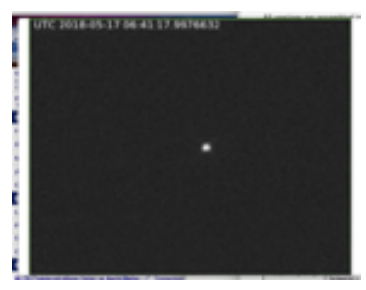

$6: 41: 28$

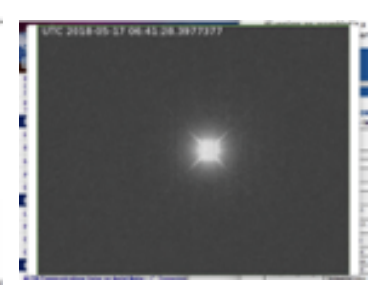

$6: 41: 39$

$6: 41: 50$
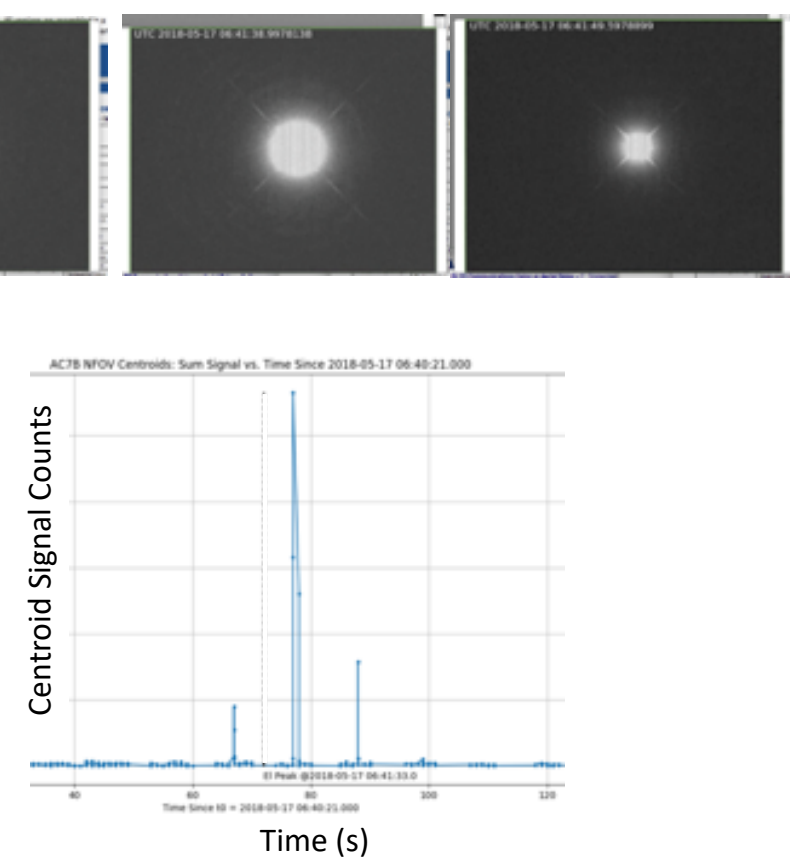

Unclassified
$6: 42: 00$

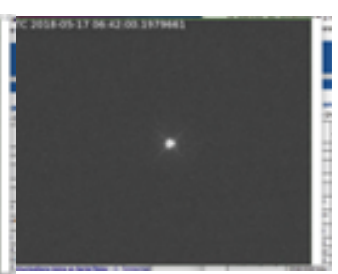

NFOV Camera Tx Power $=2 \mathrm{~W}$

$1^{\circ}$

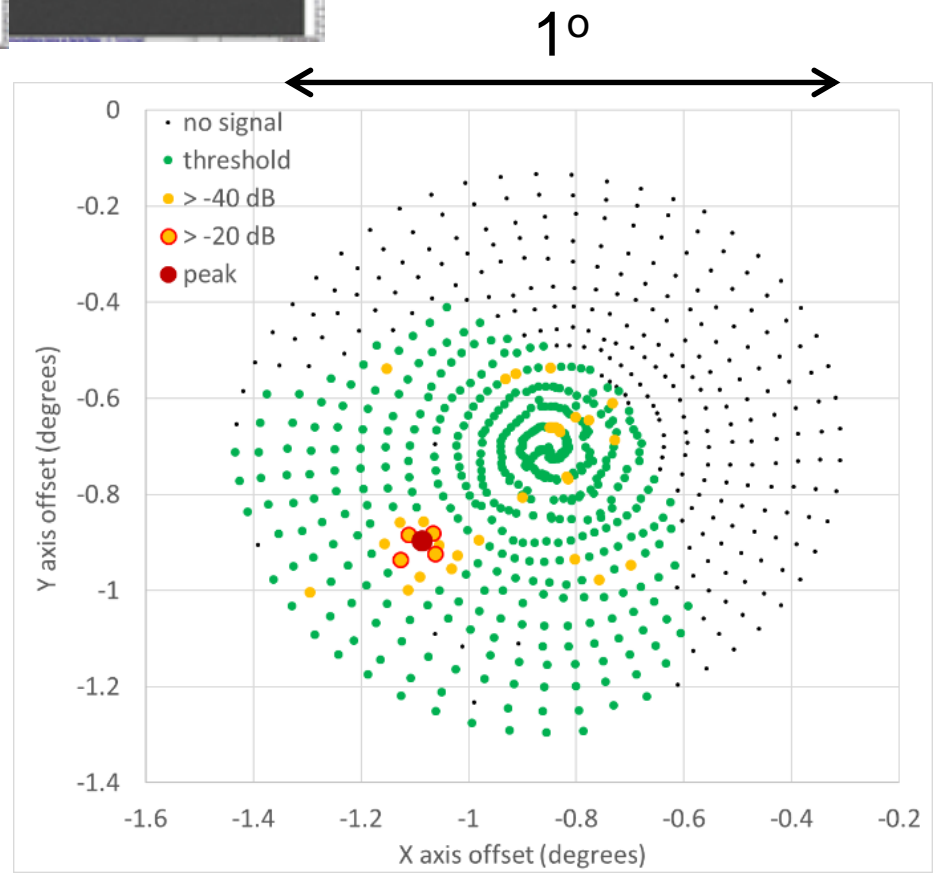




\section{OCSD - Laser Alignment Scans}

- Alignment between the star trackers and laser is determined via correlation of the star tracker pointing solution and the ground telescope observed signal intensity

- A sequence of progressively tighter spiral scans is used to hone the alignment to within the accuracy of the star tracker solutions $\sim 0.02$ deg. BER metric added to finer scans.

Example Broad Scan: $1^{0}$ w. $0.04^{\circ}$ step NFOV Sensor Metric

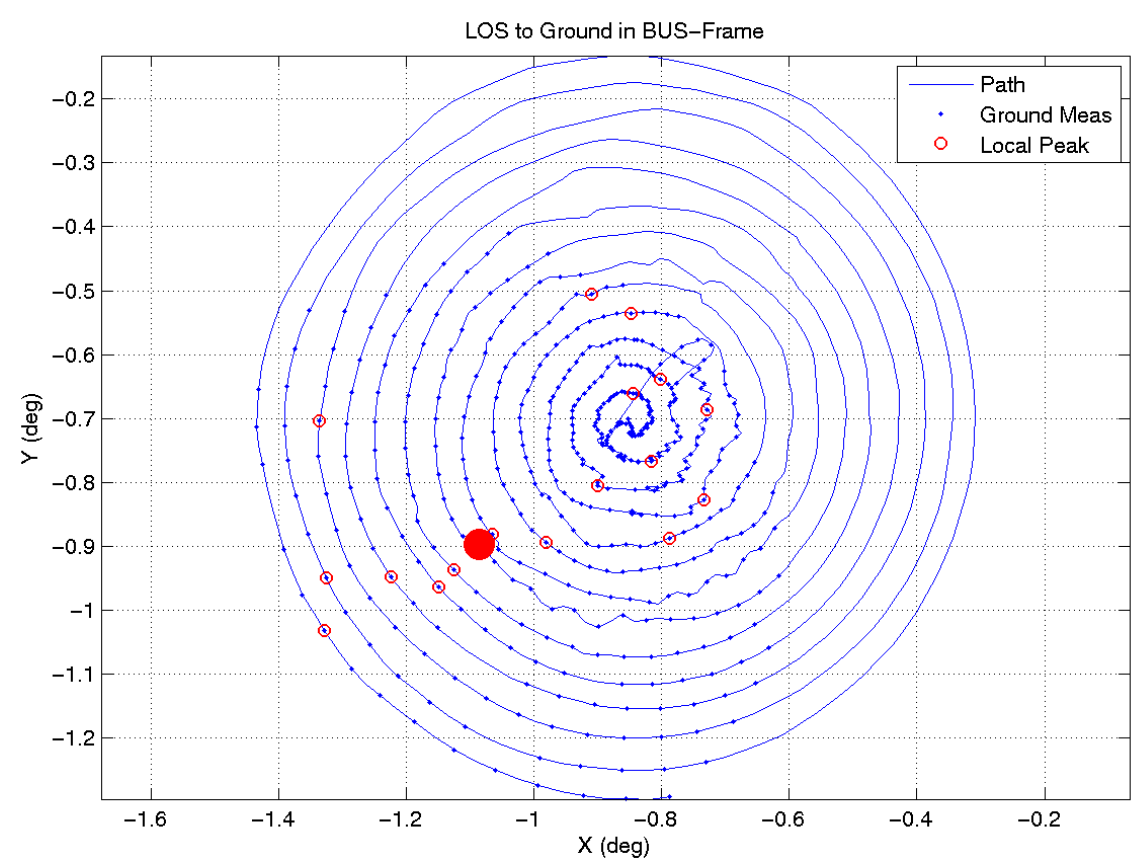

Example Narrow Scan: $\sim 0.2^{0}$ w. $0.02^{\circ}$ step BER Metric added

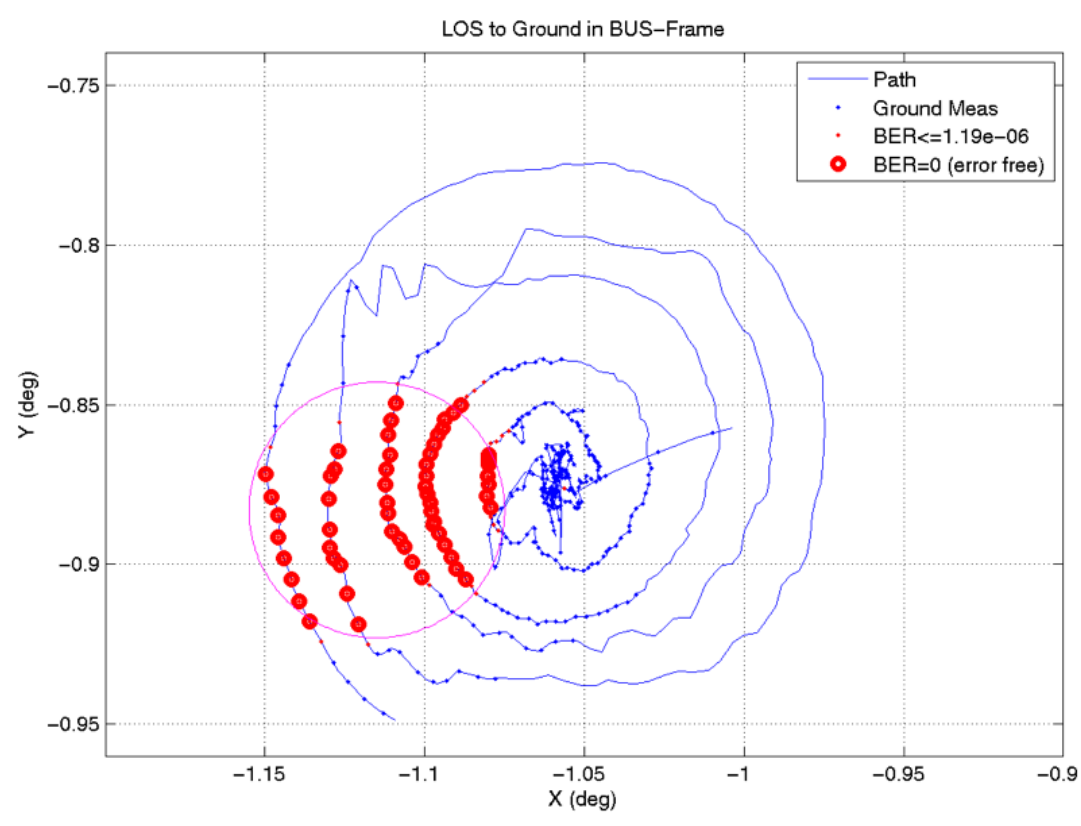

Blue lines $=$ trajectory based on star tracker readings

Blue dots = ground "hits" observed

Red dots = strong ground "hits" or low/error free BERs 


\section{OCSD - Pointing Control}

- On-orbit Control Error during laser pointing to the ground station is generally better than \pm 0.01 degrees

- "jumps" related to star tracker updates. [metric does not include attitude determination error]

- Star Tracker accuracy is currently the largest component in the system pointing error, wheel controller able to support $\sim 0.005$ deg with a more accurate attitude reference

Pointing Accuracy Budget Allocations

\begin{tabular}{|l|c|}
\hline \multicolumn{1}{|c|}{ Error Sources } & $\begin{array}{c}\text { Pointing Error } \\
\mathbf{3 \sigma} \text { (Deg) }\end{array}$ \\
\hline Payload to AD Frame Alignment (post-cal) & 0.010 \\
\hline Real-time Clock Drift & 0.005 \\
\hline Orbit Determination / Ephemeris Error & 0.003 \\
\hline Attitude Determination Error & 0.015 \\
\hline Attitude Control Error & 0.015 \\
\hline Total & $\mathbf{0 . 0 2 4}$
\end{tabular}

Mounted Star Trackers
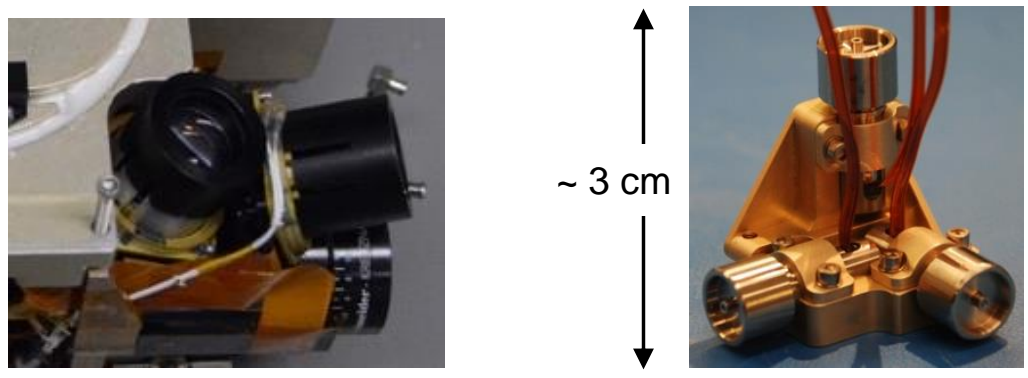

Miniature Reaction Wheels

On-orbit Control Performance

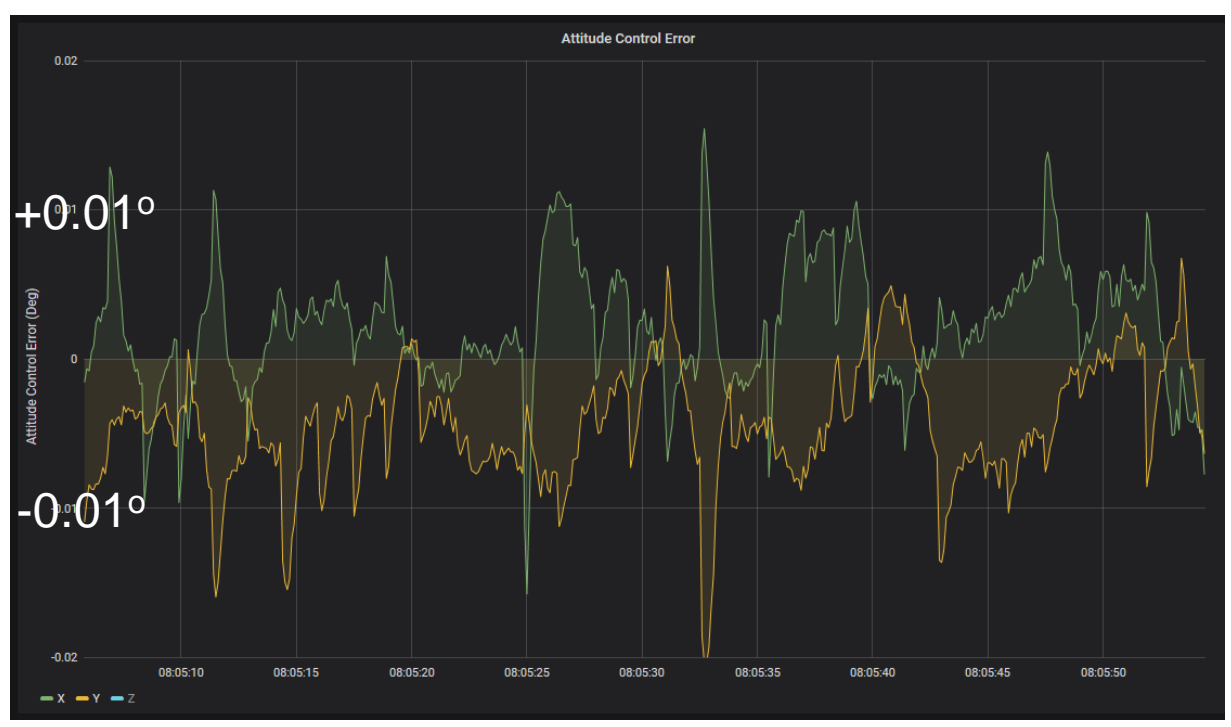

- Miniature reaction wheels and torque rods are used for actuation and momentum control 


\section{First AC-7B Data at 50 \& 100 Mbps during Spiral}

BER Captured over 100 ms intervals at $50 \mathrm{Mbps}$

BER Captured over $\sim 25 \mathrm{~s}$ at $50 \mathrm{Mbps}$
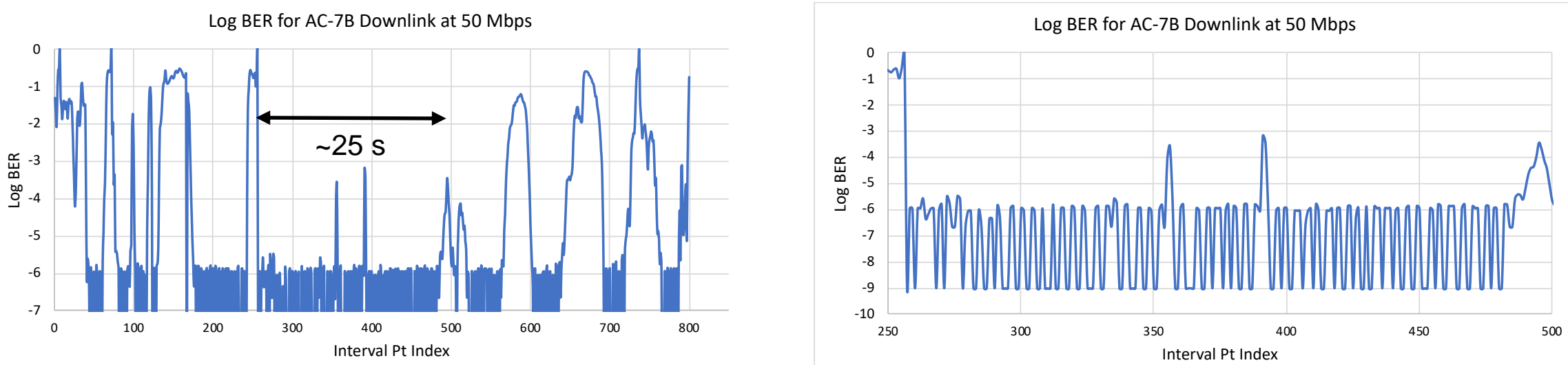

BER Captured over $\sim 100 \mathrm{~ms}$ intervals at $100 \mathrm{Mbps}$

Captured waveform/eye at $100 \mathrm{Mbps}$ Log BER for AC-7B Downlink at 100 Mbps
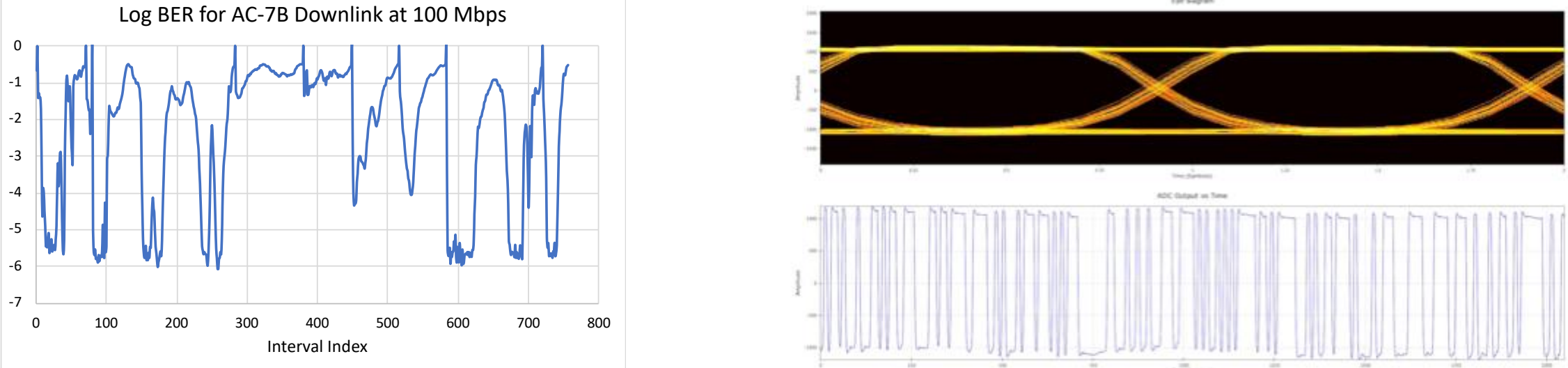

Tx Power = $2 \mathrm{~W}$; cyclical BER performance due to vehicle spiral scanning of laser pointing 


\section{Prelim Data at 200 Mbps: Spiraling + Fixed Pointing}

BER Captured over 60 s span/ 100 ms interval
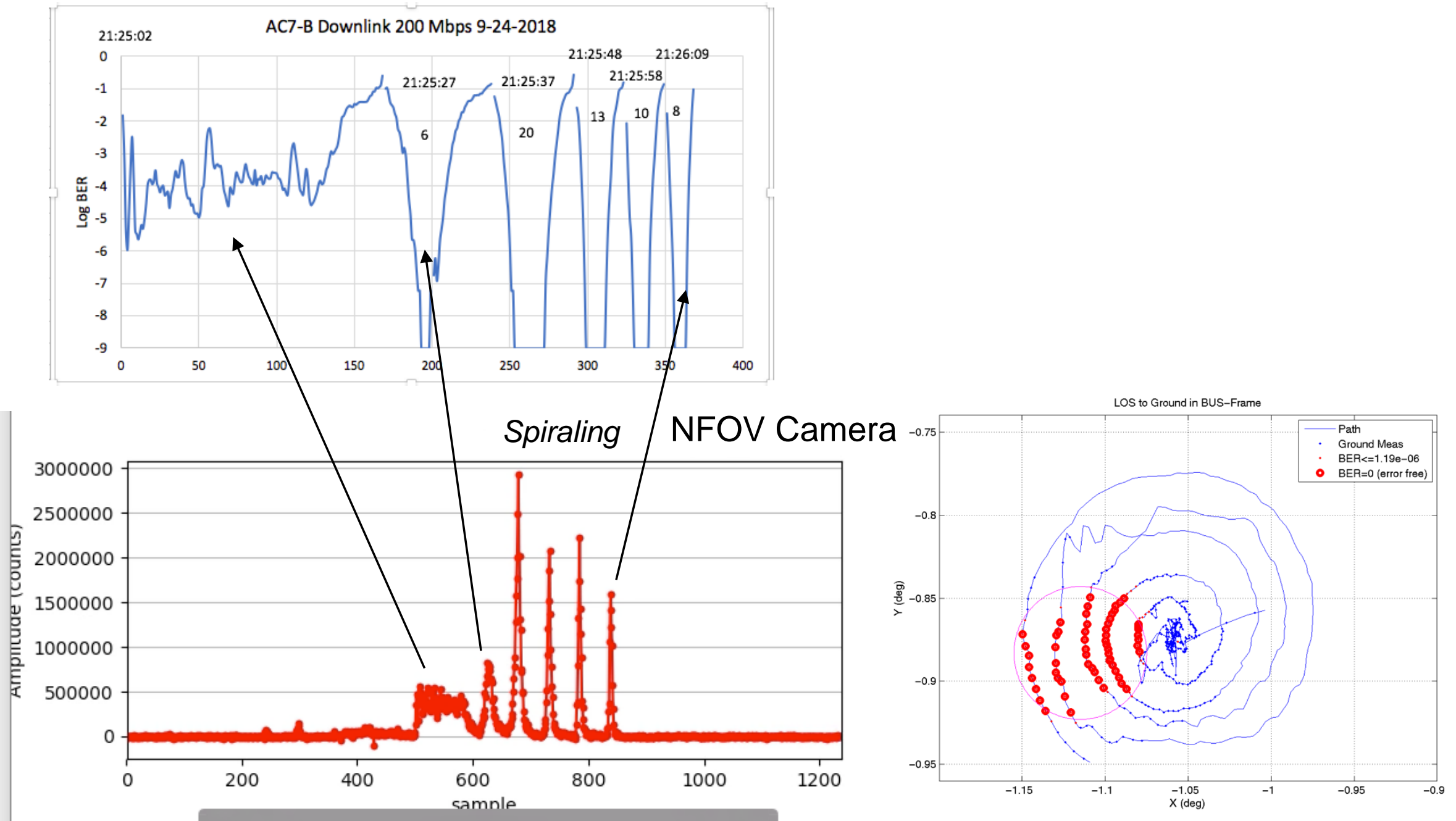

Link can sufficiently close error free if pointing is established

Unclassified 


\section{Preliminary Data at 200 Mbps: Fixed Pointing}

BER Captured over $115 \mathrm{~s}$ span out of $130 \mathrm{~s}$

$$
\text { Tx Power }=2 \mathrm{~W}
$$

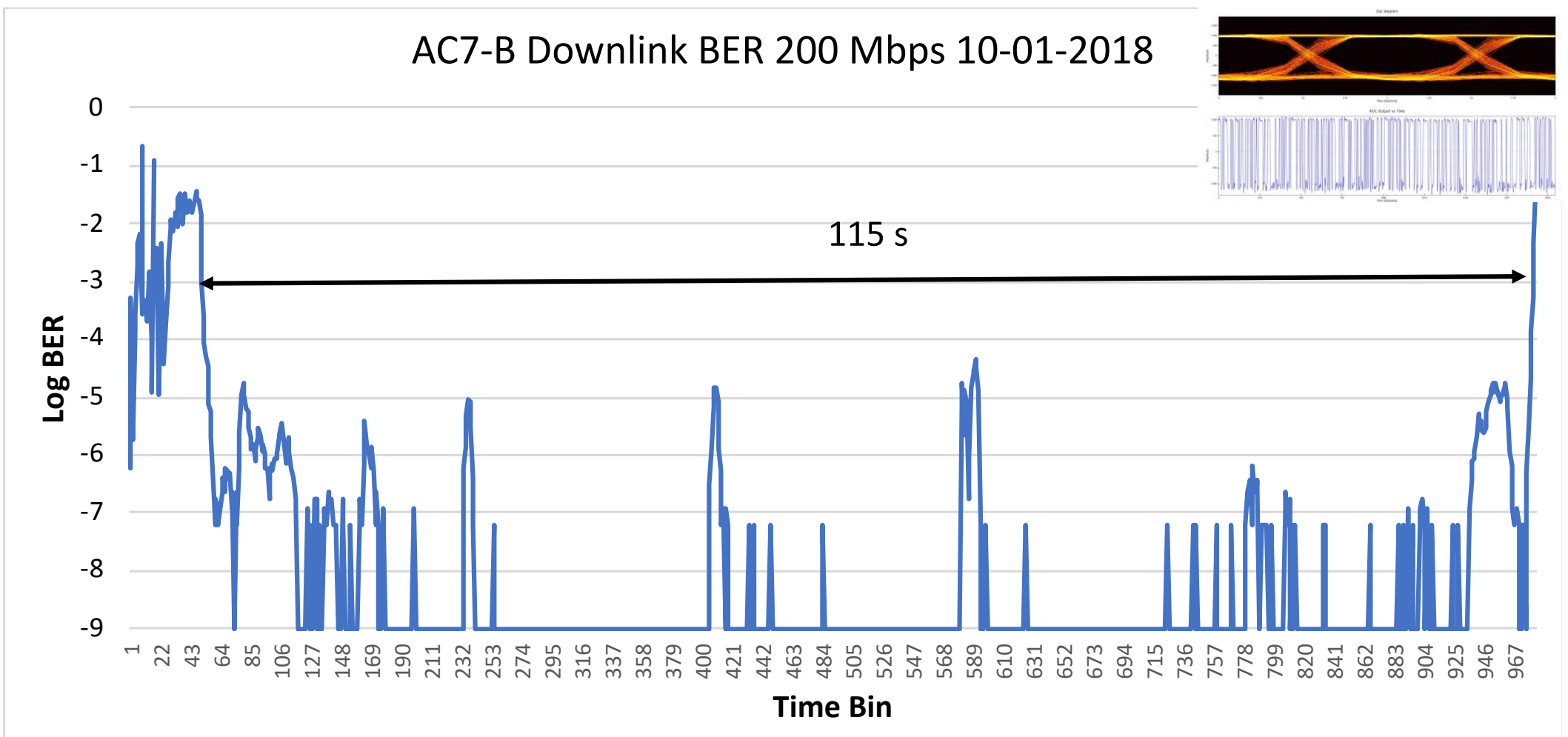

Link closed for effectively the entire engagement: no beacon, no FEC 


\section{OCSD Mission Summary}

- Two vehicles with lasercom systems launched

- Completed OCSD lasercom objective (50 - $200 \mathrm{Mbps})$

- Proof-of-principal LEO-to-ground link demonstrated with body steered cubesat

- Significant error free communication at 200 Mbps without FEC at 2 W; 2 min. link

- Links completed using star trackers for pointing control

- Accuracy of $\sim 0.02^{\circ}$

- No beacon from ground

- Initial pointing offset $\sim 1^{\circ}$ per axis (includes static boresight misalignment)

- Vehicle ephemeris and ground station configuration appears sufficient for open-loop $R x$ pointing; needs further investigation at 200 Mbps (smaller detector)

- Higher data rates to be tested for AC7 and pending Cubesat missions 


\section{Acknowledgements}

- R. Dolphus, J. Wilson, P. Carian, B. Hardy, G. Kinum, D. Hinkley and A. Berman (Aerospace)

- NASA Small Spacecraft Technology Program and the NASA AMES POC, R. Hunter 